\title{
A Case Study: 5s Implementation in Ceramics Manufacturing Company
}

\author{
Vipulkumar C. Patel and Hemant Thakkar
}

\begin{abstract}
The research work carried out to apply the $5 \mathrm{~S}$ methodology of lean manufacturing to solve the problems of a ceramic industry in India with the aim to increase the efficiency of all processes and elimination of losses in the company. The objectives of the paper is to reduce the process wastes, smooth the process flow and maintain proper quality control, improve storage facilities, safety, security and process cost savings in a company through case study. Before and after picture are taken for the applying $5 S$ methodology in a company. 5S implemented has been carried out in storage department and insulator department. After implementing of $5 S$ in the storage department the space saving is $12.91 \%$ and also certain process wastes are reduced. In insulator department the workplace became efficient and effectiveness.
\end{abstract}

Keywords--- 5S, Space Utilization, Elimination of Process Waste, Case Study

\section{INTRODUCTION}

L EAN thinking represents a set of principles and techniques for the identification and elimination of waste in manufacturing and administrative processes. $5 \mathrm{~S}$ is a technique originated from Japan and it was first developed by Hiroyuki Hirano in 1980s. It include five Japanese words Seiri(Sort), Seiton(Set in order), Seiso(Shine), Seiketsu(Standardize) and Shitsuke(Sustain). The 5S philosophy focuses on simplification of the work environment, effective workplace organization, and reduction of waste while improving safety and quality [10]. It allows the enhancement of efficiency and productivity. The $5 \mathrm{~S}$ technique is a structured program to systematically achieve total organization cleanliness and standardization in the workplace. The benefit of $5 \mathrm{~S}$ technique is improvement in productivity, quality, health and safety [1,6,7]. Through 5S methodology, the management can create an environment where quality work is comfortable, clean and safe in the organization and it can ensure the compliance to standards and will further foster continuous improvement [1]

Shahryar Sorooshian etal.(2012) They have experienced of implementing a 5S philosophy and paper involves presentation of a real case study, specifically the influence of $5 \mathrm{~S}$ on some

Vipulkumar C. Patel, PG Scholar, Industrial Engineering, G. H. Patel college of Engineering \& Technology, Gujarat, India. EmailPatelvipul599@gmail.com

Hemant Thakkar, Associate Professor, Department of Mechanical Engineering, G. H. Patel college of Engineering \& Technology, Gujarat, India.E-mail:hemantthakkar@gcet.ac.in basic work environment problems and the compensation power on the choice of implementation of 5S. This paper is simply representation of basic information with all pros and cons about the concept of 5S [1].

Harsha Lingareddy etal. (2013) This research involves the study and change in the work place of a manufacturing industry to implementation of 5S. This strategy helps in minimizing the time of manufacturing and also increases the area of work place. The solution found by $5 \mathrm{~S}$ approach solely minimizes several kinds of wastes in the production process and which finally helps in the development of the organization. An Inspection process has been executed on the basis of 5S check lists and the results analyzed to confirm great changes like increasing efficiency in production and quality, improves safety [4].

J. Michalska etal. (2007) In this paper 5S implementation results in increasing of an efficiency, safety, quality and reduction of the industry pollution. The proceedings to research clearly show that training of workers about the $5 \mathrm{~S}$ rules is very essential. The important task is to divide activities on some main steps and to maintain the continuous improvement. It is important to understand the need of executing the routine inspections of usage the $5 \mathrm{~S}$ rule. This inspection is executed by helping of so-called check list and created on its basis the radar graph of the $5 \mathrm{~S}$, which serves to estimation of the workplace [9].

Prof. S. B. Khedkar etal. (2012) This research is dealt with the implementation of 5S methodology in the S. P. Plastic Industry MIDC, Nagpur. 5S implementation impacts the instructors and workman of industry that work within the selected place. By following the 5S methodology, this research effort shows significant improvements to safety, productivity, efficiency, morale and housekeeping. The research documents improvements by using before and after pictures [7].

Gheorghe Dulhai etal. (2008) This paper presents a continuous improvement strategy, process-oriented and aiming to improve manufacturing at auto car exhaust. The improvement of auto car exhausts quality, using the " $5 \mathrm{~S}$ " rules, is accomplished at the initiative of the inferior levels of the organization coordinated and helped by the superior management. The efficient implementation of the „5S" strategy leads to a subsequent improvement of the exhaust's quality [2].

Ravinder Kumar Panchal etal. (2012) This paper focus on the methodology adopted in $5 \mathrm{~S}$ and implementation of the same in the production industry. The 5S rules bring the great changes in the company, for example: process improvement 
by costs' reduction, increasing of effectiveness and efficiency in the processes, maintenance and improvement of the machines' efficiency, safety increasing and reduction of the industry pollution and waste [6].

Derya Sevim Korkut etal. (2009) This study involves 5S system for ensuring order and discipline in the companies and ensuring the supervision of both simple and even the smallest details, has been reviewed in full details and they have been taken under the content of the research through selecting the assembly department as pilot department for $5 \mathrm{~S}$ activities which is applied at a yacht manufacturing company. The obtained results are evaluated and it has been observed that the company came to a point better than the initial status. The clearly seen of the weekly results hang on $5 \mathrm{~S}$ acknowledgment boards within the company by all personnel played an efficient role and involvement in the process. 5S approach is not a study covering a certain period of time, rather it is a method defending the requirement of the standardization and continuation of all improvements need to be perform [10].

Marko Milosevic etal. (2013) In this paper explain the methods and techniques of lean concept which uses to increase the efficiency of all processes in the company. Also show the results of the level of implementation this method in international and domestic production companies. It can conclude that large companies pay much attention to "lean" concept, both because productivity, and the satisfaction of their employees [5].

P. M. Rojasra etal. (2012) This paper explain the implementation of 5S methodology in the Krishna Plastic Company, Udhyognagar, Amreli, Gujarat. Out of the available various lean manufacturing techniques, 5S offers good potential for required improvement. Ten week study is carried out in the company. The results after the 5S implementations states that production system efficiency is improved from $67 \%$ to $88.8 \%$ in the successive week [3].

Jose H. Ablanedo-Rosas etal. (2010) In this paper results of an empirical study applied to some Mexican organisations with the aim of understanding their implementation experience, empirical relationships, and ongoing challenges associated with the $5 \mathrm{~S}$ practice are elaborated. The $5 \mathrm{~S}$ practice is used as the basis for advanced quality and continuous improvement philosophies and the organisation measures the benefits from 5S implementation such as quality improvement. The $5 \mathrm{~S}$ practice is worthwhile for production and service organisations and is universal to all organisations. The big challenge is how to incorporate the $5 \mathrm{~S}$ practice in everyone's (employee's) life [8].

\section{A. Review Remarks}

The recommendation to implement $5 S$

- To make the 5S practices more influential the top management are required to fully support this activity all through the company. In order to make the top management aware of the effectiveness of the 5S, they have to be shown the performance of product quality of this approach.

- The organization should institute a system of benchmarking with other companies which are successful and make reference on a regular basis with the member of the Quality Team which will provide assistance to the companies in terms of further comprehending its vision and mission.

- The involvement of all employees in the all departments in the program 5S. All staff should understand the five good reasons 5S program should be practiced at the workplace as it will result in a clean workplace with higher productivity, having a high quality, reducing cost, to ensure timely delivery and consequently, it is a safe workplace.

\section{Methodology OF 5S}

A method commonly used by a manufacturing company to achieve an effective, efficient, and organized work environment, so as to boost productivity, reduce cost, and improve quality standards. 5S include five japanies word which are seiri, seiton, seiso, seiketsu, and shutsuke.

$5 S$ programs have been implanted in organizations and the world as a way to improve production values while also improving employee morale and safety. The 5S methodology may be applied to most workplace scenarios in a short period of time due to its simple nature. The before and after picture are taken for implementation of 5S methodology in a company.

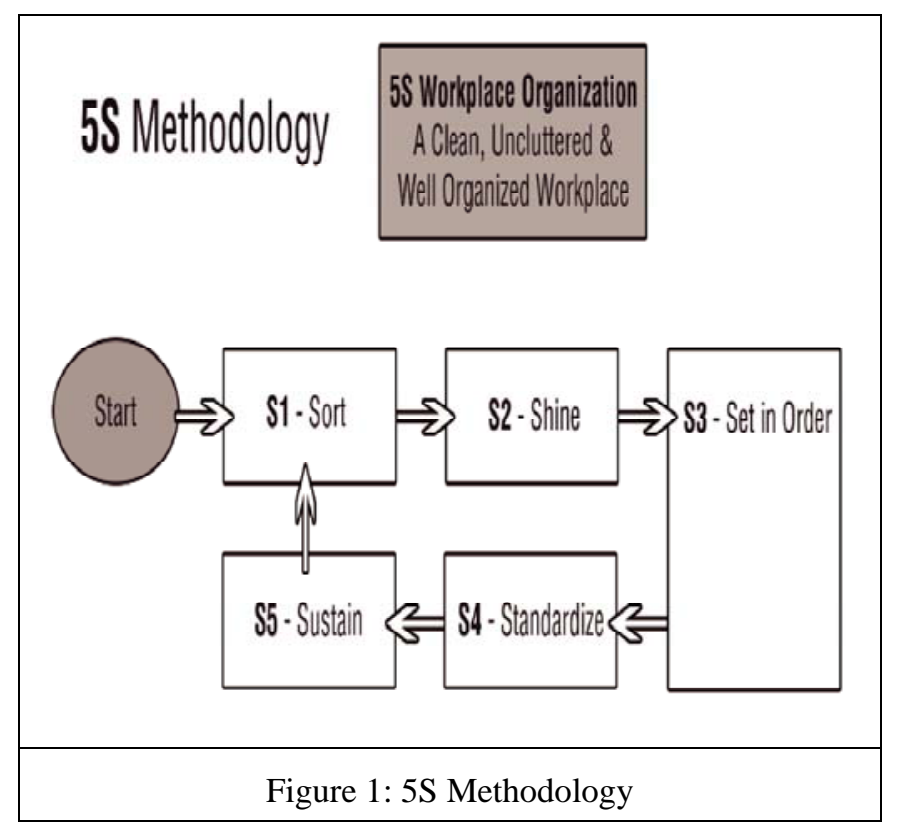

A. Seiri

Sorting items which are not necessary and segregating and disposing of goods that are not needed at work systematically. Separation process is helpful in determining the necessary materials at the present or the future and should be stored in a designated storage area. Unnecessary items will be disposed [1].The arrangement used for keeping each material in the company at correct place is named as sort. The defective or rarely used material and equipment's in the company cause the demolishment of the workplace's order and decrease in the work efficiency [10]. This leads to fewer hazards and less clutter to interfere with productive work [9]. 


\section{B. Seiton}

Especially important is visualization of the workplace in order to focuses on the need for the workplace. Tools, equipment, and materials must be systematically arranged for the easiest and the most efficient access [7]. The main objectives of Seiton are forming a regular workplace, avoiding time loss while searching the material and mistake proofing work [3].

\section{Seiso}

Point outs the need and necessity of clean and neat work place. Cleaning should become a daily activity. The dust, dirt and wastes are the source of untidiness, indiscipline, inefficiency, faulty production and work accidents. There for Work place should be cleaned at regular intervals. Every tool and equipment should be restored at their own places after their use [4].

\section{Seiketsu}

Establishing the standard rules to maintain the perfect hygiene and safe environment at the workplace [2]. The goal of this step is keeping, standardize, and preventing from this present order and regularity. The necessary systems are formed in order to maintain the continuance of these good practices at the workplace [10]. Standards should be very communicative, clear and easy to understand. Regarding this during preparation and improving, it should be involved all participants of the process on the given workplace, it means direct workers [9].

\section{E. SHITSUKE}

Always Practice (Shitsuke): Train employees disciplined for practicing $5 \mathrm{~S}$ system continuously so that the habits and culture within the organization. This is by far the most difficult $\mathrm{S}$ to implement and achieve. People tend to resist change and even the most well-structured 5S plan will fail if not constantly reinforced. It creates an educating, cooperating, discipline system and inspection for protecting the best present situation [1].

\section{RESULT AND DISCUSSION}

\section{A. Sort}

At beginning of this effort, several areas of this storage are disorganized and untidy. Figure (2) illustrates red tagging of unnecessary materials.

The purpose of red tagging was to identify unnecessary items that occupied space in the storage department. The strategy is to create more space by better organizing the items and equipment in permanent storage places or disposing of the item if it is not needed.

After all the red-tagged items and equipment are moved out of from the department, extra space is generated in the store. These areas are then utilized for smoother materials and traffic flow.

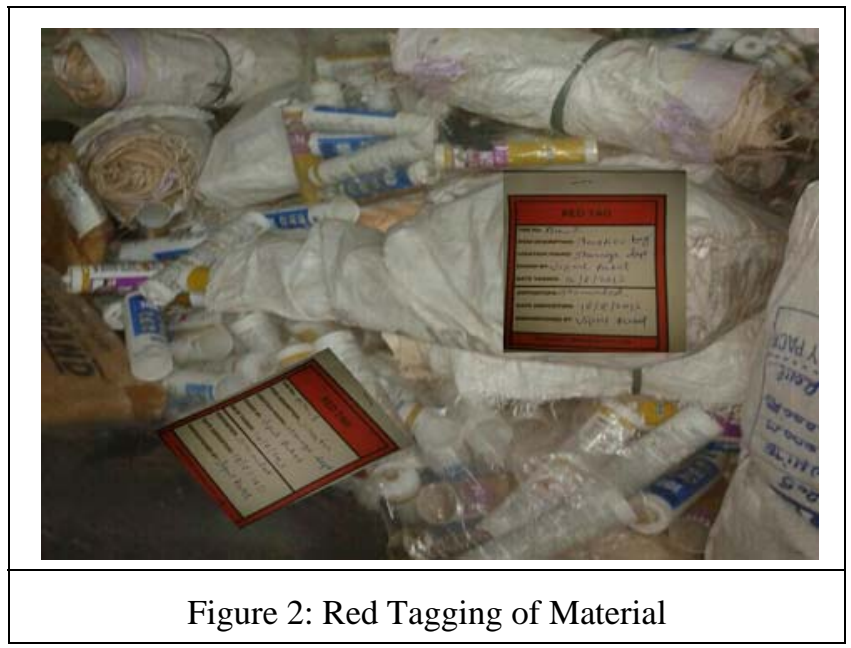

Benefits

- Increased Productivity - The purpose of individual work areas will be more apparent, leading to a highly efficient workflow.

- Workers will be more satisfied with their environment Employee morale would increase as junk items or materials that are potential health hazards are identified and removed.

- The end product of your labours will be much improved as full attention can be paid to production.

- Employees will no longer need to focus on tangential tasks such as locating tools implementing their own organization systems.

\section{B. Set in Order}

\section{a. Organization of Work Station}

The next step after identifying the unneeded item is to organize the needed item as per the specific job requirement in each station. In this process, tried to use as much of a visual approach as possible to ease the organization process and make work easier for the worker. Pictures (Figure 3) are taken to differentiate the after and before condition of a storage department, thereby highlighting the importance of this process.

The major benefits of organizing the work station are to ensure clear visibility of needed items, increasing efficiency of job performed, reducing the run time, and increasing the productivity.

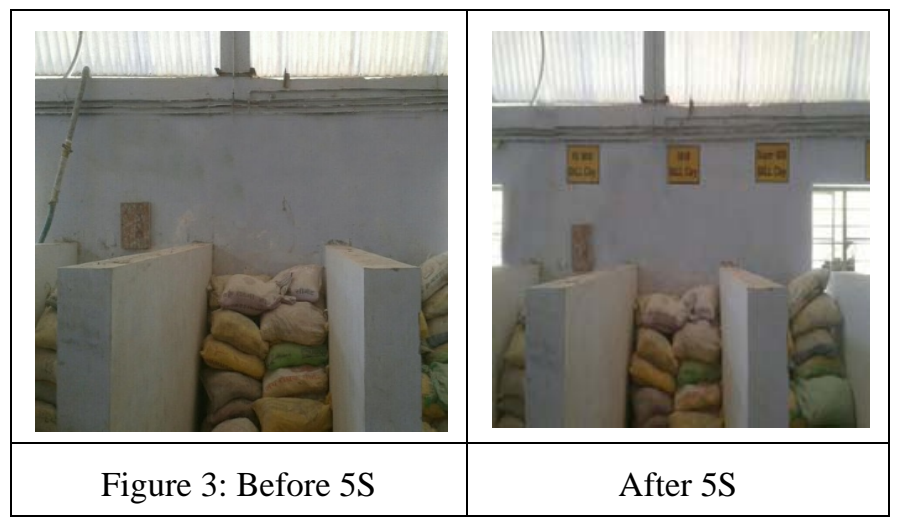


Figure 4, In Turning department the workplace is outline by the yellow line. So that is to transportation of men, materials, equipment movement in the department is very easy and reduce the product damage and accident.

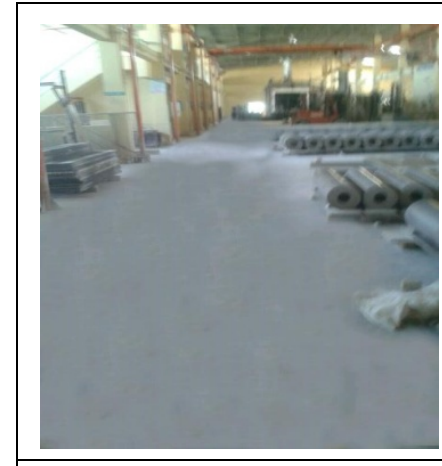

Figure 4: Before 5S



After 5S
Labeling on the vertical lathe machine shown in the before and after picture in figure 5.

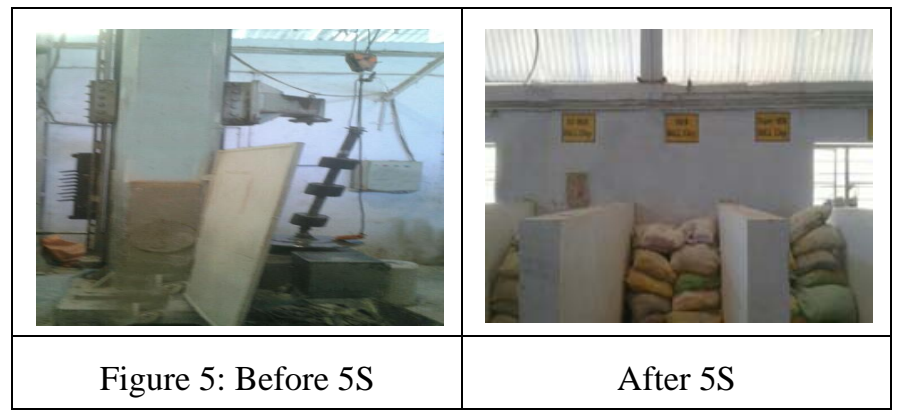

Benefits

- Process improvement (increasing of effectiveness and efficiency).

- Shortening of the time of seeking necessary things.

- Safety improvement.

\section{Clean / Shine}

In order to maintain a clean and organized work atmosphere, cleaning supply shadow board are used. Several areas in the work station have problems keeping things clean. This sometimes comes from not being able to find cleaning supplies. By creating the cleaning supply shadow boards and locations for those supplies, everyone knew where to get them when needed and where they belong after the completion of work. The importance of keeping each station was paramount and awareness is created among the associates holding them accountable for their specific work station. Also, trash bins (fig. 6) are labelled and located at convenient locations to ease the implementation process.

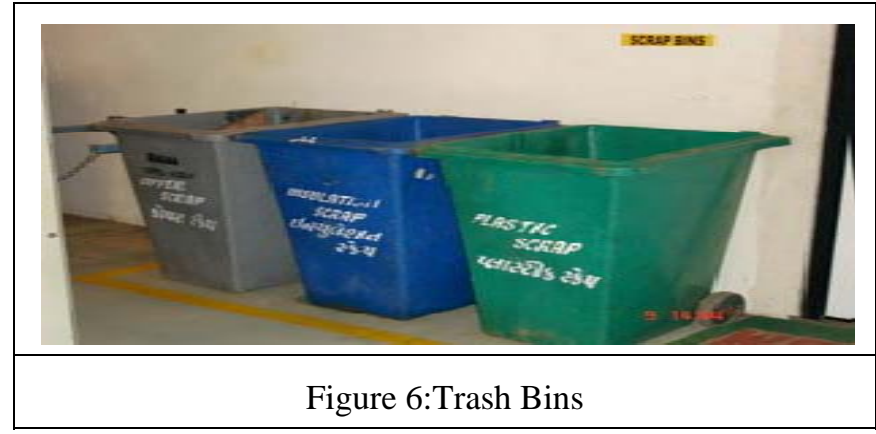

Benefit:

The benefits of a clean workplace are readily apparent after a short period of time. Employee morale increases, and the most productive time can be dedicated to the most important tasks.

- Maintenance the cleanness of devices.

- Maintenance the clean workplace, easy to check.

- Quick informing about damages (potential sources of damages).

- Improvement of the work environment.

- Elimination of the accidents' reasons.

\section{Standardize}

In order to standardize achieved, the workers from the department have agreed upon that everyone should contribute to daily clean-up of the working place. Moreover, in the end of the working week a more detailed clean-up is performed, the performance of which is controlled by a dedicated employee on a week-clean up duty.

The task and responsibility are allocated to the worker for daily cleanup activity.

GEMBA board (Figure 7), used to evaluate all the key performance indicators (KPI); namely safety, quality, productivity, labour absenteeism, and break down in the pugmill of insulator department. It is a visual method to track all the daily floor activities and also provide for the posting of root causes and countermeasures when the KPIs do not meet the goal. Also the skill record of employee is shown in chart.

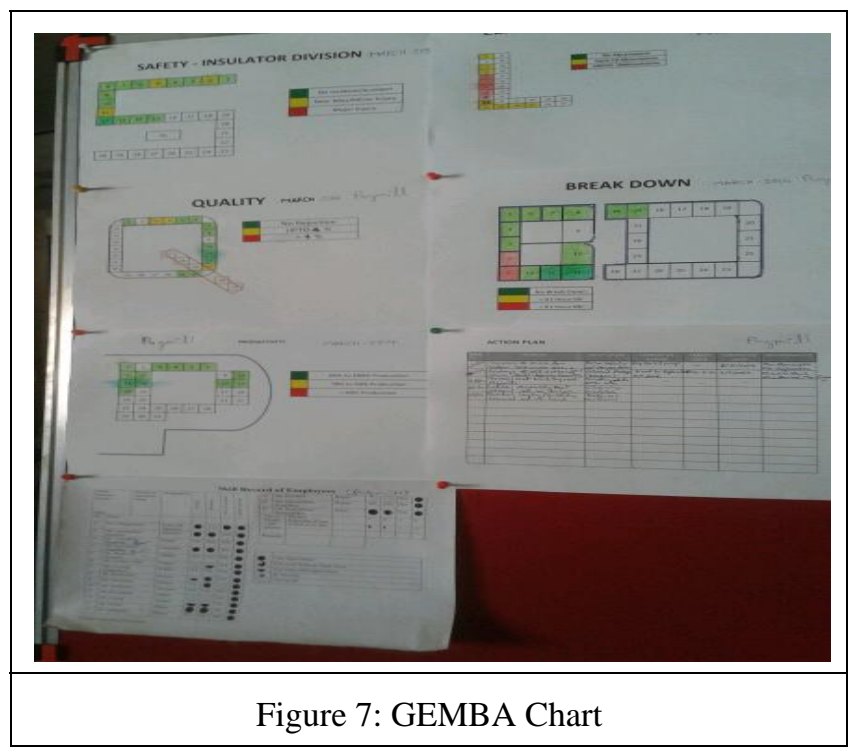


Benefit:

- Safety increasing and reduction of the industry pollution.

- Working out the procedures defining the course of processes

\section{E. Sustain}

After the successful implementation of the 5S process, the discipline to sustain is of the most importance. Proper awareness, correct structures and procedures, support from worker and management, adaptability to $5 \mathrm{~S}$ is vital for continuous improvement. In order to achieve that, a $5 \mathrm{~S}$ observation sheet is prepared to aid in the implementation of the $5 \mathrm{~S}$ process. The observation was done on a monthly basis and the results are analyzed.

Benefits:

- Increasing of the awareness and morale.

- Decreasing of mistakes quantity resulting from the inattention.

- Proceedings according to decisions.

- Improvement of the internal communication processes.

- Improvement in the interaction of human relations.

\section{F. Storage Space Utilization}

In a storage department there are many raw materials, tools, and machine components are stored. Several data are collected from the checklist. Following table 1 gives the raw materials size/weight, frequency use of materials in month, and location of the materials. These data are collected for the better arrangement of the materials in the store.

Table 1: Data Collection of Material

\begin{tabular}{|c|l|c|c|c|}
\hline $\begin{array}{c}\text { Sr. } \\
\text { No. }\end{array}$ & Material & Size/weight & $\begin{array}{c}\text { Freq. of } \\
\text { use(month) }\end{array}$ & Location \\
\hline 1 & Steel wool & 20 & 1 & $\mathrm{~A}$ \\
\hline 2 & Gas pipes & 15 & 6 & $\mathrm{~A}$ \\
\hline 3 & Blower & 5 & 6 & $\mathrm{~A}$ \\
\hline 4 & $\begin{array}{l}\text { Casting } \\
\text { product die }\end{array}$ & 25 & 12 & $\mathrm{~A}$ \\
\hline 5 & Net jali & 25 & 2 & $\mathrm{~A}$ \\
\hline 6 & Belt & 400 & 2 & $\mathrm{~A}$ \\
\hline 7 & $\begin{array}{l}\text { emery } \\
\text { wheel }\end{array}$ & 10 & 8 & $\mathrm{~A}$ \\
\hline 8 & Valve cock & 10 & 1 & $\mathrm{~A}$ \\
\hline 9 & $\begin{array}{l}\text { Ele. } \\
\text { Material }\end{array}$ & 25 & 1 & $\mathrm{~B}$ \\
\hline 10 & Bearing & 500 & 1 & $\mathrm{~B}$ \\
\hline 11 & $\begin{array}{l}14,16,18 \\
\text { cone }\end{array}$ & 10 & 2 & $\mathrm{~B}$ \\
\hline 12 & Nut \& bolt & 20 & 1 & $\mathrm{~B}$ \\
\hline 13 & Color & 5 & 1 & $\mathrm{~A}$ \\
\hline 14 & Flange & 1000 & 3 & $\mathrm{~A}$ \\
\hline 15 & Plastic bag & 100 & 1 & $\mathrm{~A}$ \\
\hline
\end{tabular}

In figure (8) the frequency of size and weight, observed that flanges, belts and bearing are used in higher quantities in the organization.

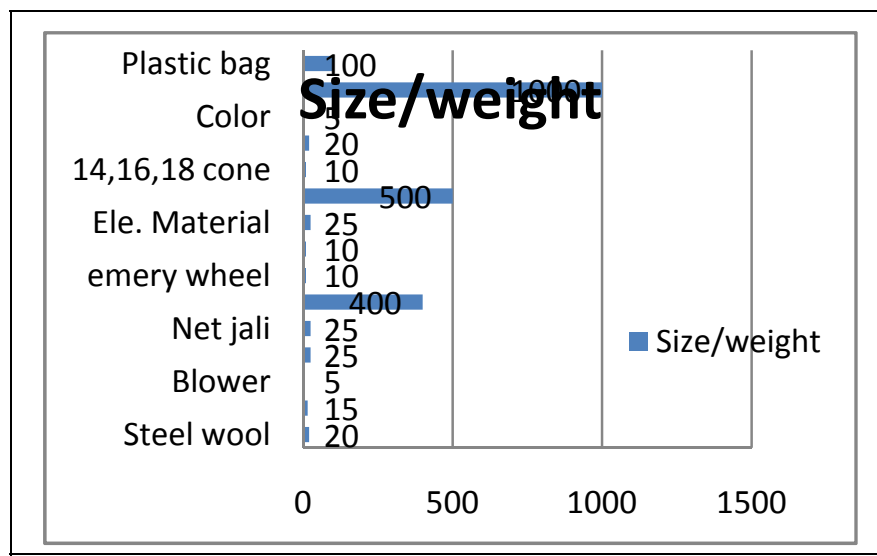

Figure 8: Frequency Use of Material In Size/ Weight

In Figure (9) shown that the smaller frequency materials are indicates that they are used very frequently and hence such material consumption is high.

\section{Freq. of use(month)}

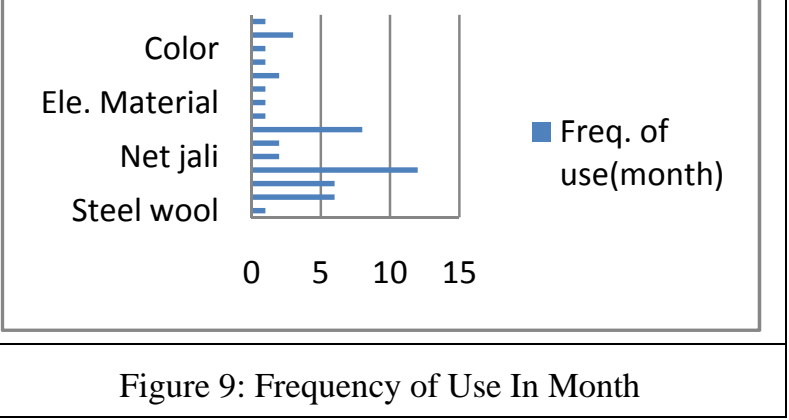

The new arrangement of location of materials based on frequency of use is suggested. For design of storage layout the FSN analysis is carried out. FSN analysis is based on frequency of use item in the store. In this analysis

F- Stands for the fast moving item are corresponds to frequency use of item.

S-stands for slow moving item correspond to less frequently use.

$\mathrm{N}$ - Means Non-moving item will be not issue for longer period.

The suggested layout arrangement of materials is shown in figure 10. 


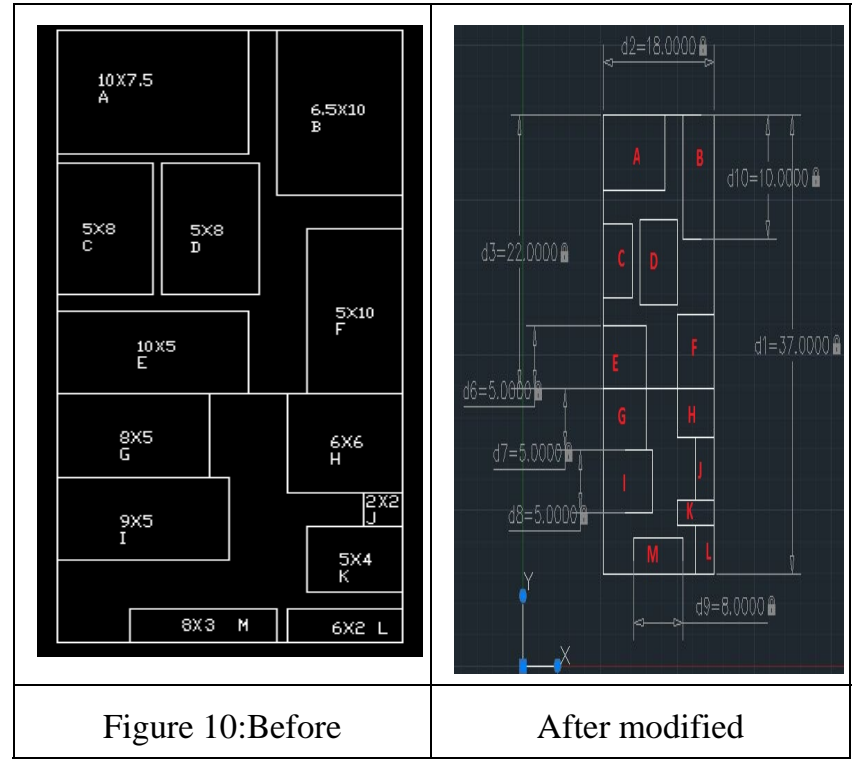

According to the revised layout new locations are defined for the better arrangement of materials. This arrangement saves about $12.91 \%$ space of the store.

Table 2: Material Area

\begin{tabular}{|c|c|c|c|c|c|}
\hline $\begin{array}{l}\text { Sr. } \\
\text { No. }\end{array}$ & $\begin{array}{l}\text { Name of } \\
\text { materials }\end{array}$ & Quantity & location & $\begin{array}{c}\text { Area } \\
\text { before } 5 \mathrm{~s} \\
\text { imp. }\end{array}$ & $\begin{array}{c}\text { Area after } \\
\text { 5s imp. }\end{array}$ \\
\hline 1 & $\begin{array}{l}\text { Tested } \\
\text { flange }\end{array}$ & 800 & A & 75 & 60 \\
\hline 2 & $\begin{array}{l}\text { Without } \\
\text { tested } \\
\text { flange }\end{array}$ & 300 & A & 50 & 35 \\
\hline 3 & $\begin{array}{l}\text { Plastics } \\
\text { bag }\end{array}$ & 20 & A & 40 & 30 \\
\hline 4 & $\begin{array}{l}\text { Mix raw } \\
\text { material }\end{array}$ & 50 & $\mathrm{~A}$ & 50 & 42 \\
\hline 5 & Rack & 10 & A & 65 & 50 \\
\hline 6 & $\begin{array}{c}\text { Nuts \& } \\
\text { bolts }\end{array}$ & 20 & B & 40 & 39 \\
\hline 7 & $\begin{array}{l}\text { Storage } \\
\text { data }\end{array}$ & 200 & B & 40 & 35 \\
\hline 8 & Bearing & 1000 & B & 12 & 12 \\
\hline 9 & $\begin{array}{l}\text { Valve } \\
\text { cock }\end{array}$ & 10 & B & 24 & 24 \\
\hline 10 & $\begin{array}{c}\text { Raw } \\
\text { materials }\end{array}$ & 50 & B & 20 & 12 \\
\hline 11 & $\begin{array}{l}\text { Inspection } \\
\text { area }\end{array}$ & 1 & A & 50 & 42 \\
\hline \multirow[t]{2}{*}{12} & Office & 3 & B & 45 & 40 \\
\hline & & & & 511 & 421 \\
\hline
\end{tabular}

Calculation:

- Total area of storage dept.= 666 sq. feet

- $\quad$ Occupied Area before $5 \mathrm{~S}$ implementation= 511 sq. feet

$$
(511 * 100) / 666=76.12 \%
$$

- Occupied Area after 5S implementation= 421 sq. feet $(421 * 100) / 666=63.21 \%$

- $\quad$ Total storage area saving $=12.91 \%$
The Benefits derived from revising the materials arrangement in storage department:

- The space utilizing in storage department

- Time saving in find out materials

- Increase work environment

- Increase employee performance and morale

\section{G. Process Improvement in Insulator Department}

The process flow diagram is shown in figure 11 for the understanding the movement of the in-process materials. The manufacturing of ceramics components is carried out in batches. Some process is carried out on individual basis, and certain process is carried out on lot basis.

Using the operation data the flowchart is drawn for understanding the process of ceramic "insulator" product. There are two methods for the manufacturing of insulators; one is lot-wise process and individual product-wise process.

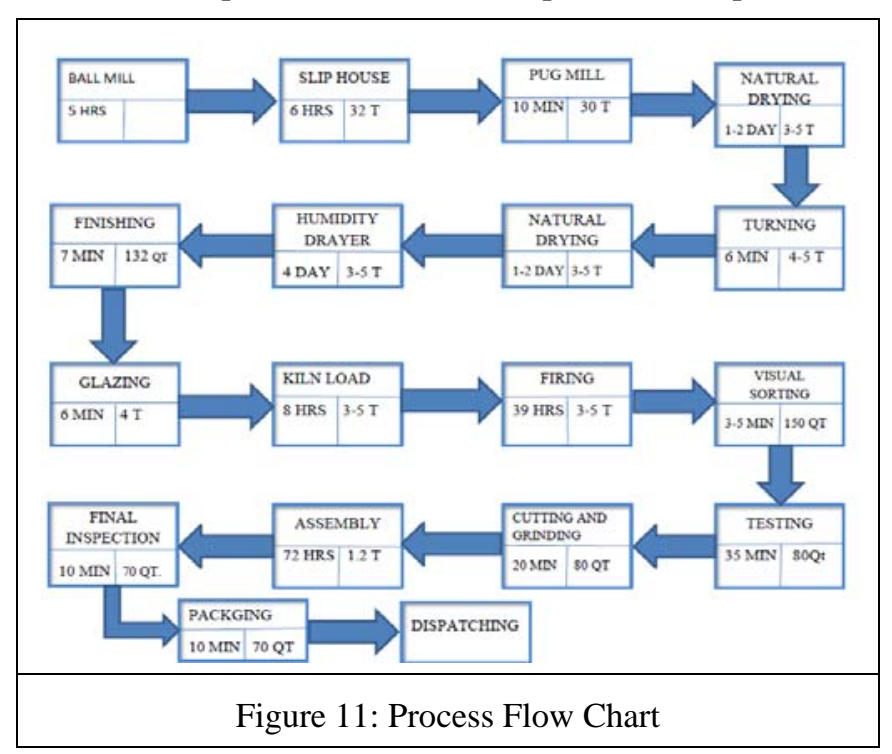

Below graph indicates that testing consumes maximum process time on individual basis. The quality control is very essential to satisfaction of customers, so it cannot be eliminated or simplified. As there is $100 \%$ inspection and testing of all ceramic components, to balance the processing time multiple test set up should be developed to eliminate the bottleneck in the production of ceramic components.

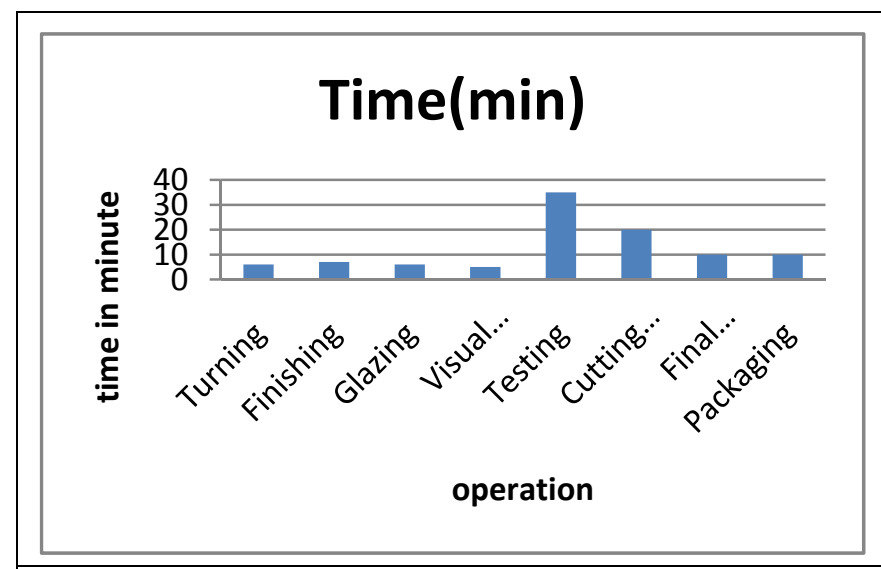

Figure 12: Individual Processes 


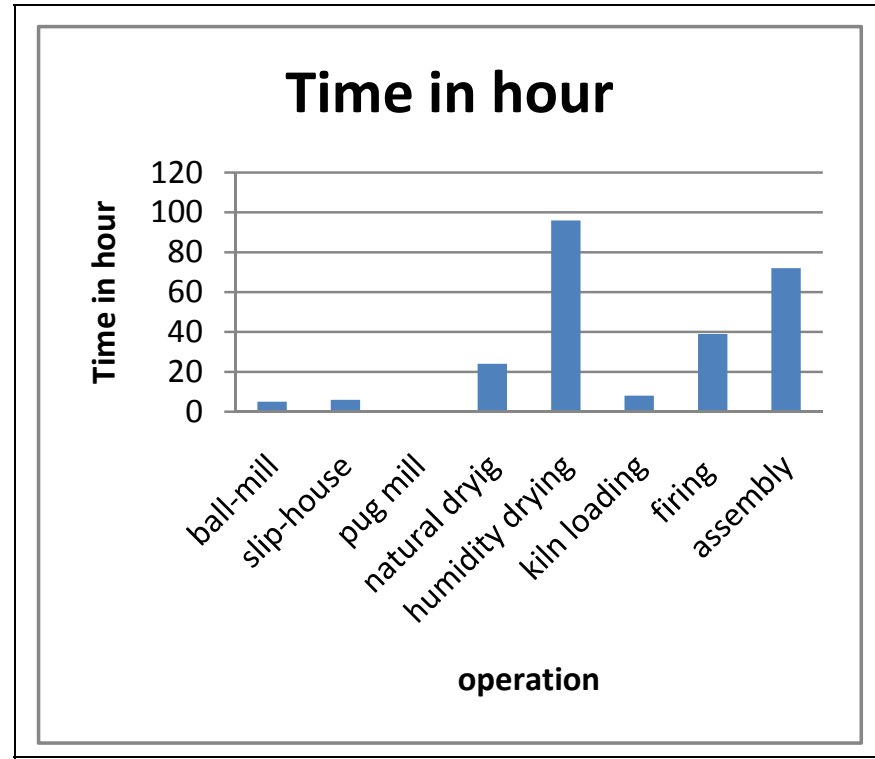

Figure 13: Lot Processes

In lot process maximum time is consumed in humidity drying and assembly of the products. There is possibility to modify the process or processing time since they are basic requirements of the manufacturing process. So, at the testing process the production should be increase.

\section{a. Observation}

- It is observed from the data that improvement is not possible in lot processes and natural drying process.

- The process can be improved by making certain changes in the individual component process.

- The production process can be made efficient by eliminating bottleneck condition of the process.

\section{b. Suggestion}

- The testing of components is $100 \%$ basis.

- The testing consumes 35 min. per components.

If this bottle neck can be resolved by adding one more testing machine, the production process can be made efficient.

- The current rate of inspection is 80-units/day. If one machine is added the capacity can be increased up to 160-units/day.

- Visual sorting process is 132 units/day, hence maximum output will be 132 units/day will be possible.

\section{CONCLUSION}

- Due to implementation of $5 \mathrm{~S}$ and visual management system (GAMBA), there was improvement in space utilization, safety of the employees, less scope of error, increased productivity, and improved inventory system, also increasing of machines' efficiency, maintenance the cleanness of devices, maintenance and improvement of the machines' efficiency, maintenance the clean workplace, easy to check, quick informing about damages (potential sources of damages),improvement of the work environment, elimination of the accidents' reasons in the company.
- The result of implementation of $5 \mathrm{~S}$ is $12.91 \%$ sq. $\mathrm{ft}$. space saving in the storage department, so that movement of men, material is reduced.

- Awareness of the 5S concept indirectly improved the morale of employees with better working environment.

- Periodically $5 \mathrm{~S}$ scorecards should be checked and $5 \mathrm{~S}$ auditing should be carried out for long term benefits to the organization.

\section{ACKNOWLEDGMENT}

My Sincere thanks to my guide Dr. Hemant Thakkar, for providing in my research work. I express my thanks to my Institution namely G. H. Patel College of Engineering and Technology for providing me with a good motivation, environment and facilities like Internet, books, computers and all that as my source to complete this research work. My heart-felt thanks to my family, friends and colleagues who have helped me for the completion of this work.

\section{REFERENCES}

[1] ShahryarSorooshian, MeysamSalimi, ShanthiBavani, HastiAminattaheri, "Experience of 5S Implementation", Journal of Applied Sciences Research, 2012, vol. 8(7), 3855-3859.

[2] Gheorghe DULHAI, "The 5S strategy for continuous improvement of the manufacturing process in autocar exhaust”, Journal of Management \& Marketing, 2008, Vol. 3(4), 115-120.

[3] P. M. Rojasra, M. N. Qureshi, "Performance Improvement through 5S in Small Scale Industry: A case study", International Journal of Modern Engineering Research. 2013, Vol. 3(3), 1654-1660.

[4] HarshaLingareddy, G.Sahitya Reddy, K.Jagadeshwar, "5S as a tool and strategy for improving the work place”, International Journal of Advanced Engineering Technology, 2013, Vol. 4(2), 28-30.

[5] Marko Milosevic, Ivan Macuzic, Petar Todorovic, Marko Djapan , Evanthia Giagloglou , jordje Vuckovic, "Implementation of 5S system as a factor for improving the quality management", 7th International Quality Conference, Center for Quality, Faculty of Engineering, University of Kragujevac May 24-2013.

[6] Ravinder Kumar Panchal, "Improving the organization through 5S methodology”, Proceedings of the National Conference on Trends and Advances in Mechanical Engineering, YMCA University of Science \& Technology, Faridabad, Haryana, Oct 19-20, 2012.

[7] Prof. S. B. Khedkar, Prof. R. D. Thakre, Prof. Y. V. Mahantare, Mr. Ravi Gondne, "Studyof Implementing 5S Techniques in Plastic Moulding”, International Journal of Modern Engineering Research, 2012, Vol.2 (5), 3653-3656.

[8] Jose H. Ablanedo-Rosas, Bahram Alidaee, Juan Carlos Moreno and Javier Urbina "Quality improvement supported by the 5S, an empirical case study of Mexican organisations", International Journal of Production Research,2010, Vol. 48 (23), 7063-7087.

[9] J. Michalska, D. Szewieczek, "The 5S methodology as a tool for improving the organisation”, Journal of Achievements in Materials and Manufacturing Engineering, October 2007, Vol. 24(2), 211-214.

[10] DeryaSevimKorkut, NevzatCakıcıer, E.SedaErdinler, GökselUlay and AhmetMuhlisDogan, "5S activities and its application at a sample company”, African Journal of Biotechnology April 2009, Vol. 8 (8), 1720-1728.

[11] Mujib baig, Prasanth, "Implementation Of Lean Tools \& Techniques In Fabrication Industry" Proceedings of the National Conference on Manufacturing Innovation Strategies \& Appealing Advancements, April 19, 2013. 


\section{BIOGRAPHY}

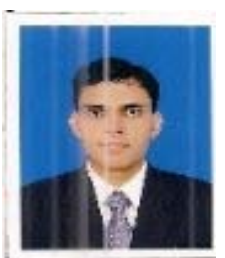

Vipulkumar C. Patel ${ }^{1}$, PG Scholar, Industrial

Engineering, G. H. Patel college of Engineering \&

Technology, Gujarat, India,Patelvipul599@gmail.com ${ }^{1}$

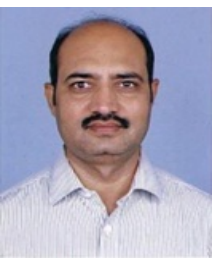

Dr. Hemant R. Thakkar ${ }^{2}$, Associate Professor,

Department of Mechanical Engineering, G. H. Patel college of Engineering \& Technology, Gujarat, India,hemantthakkar@gcet.ac.in ${ }^{2}$ 